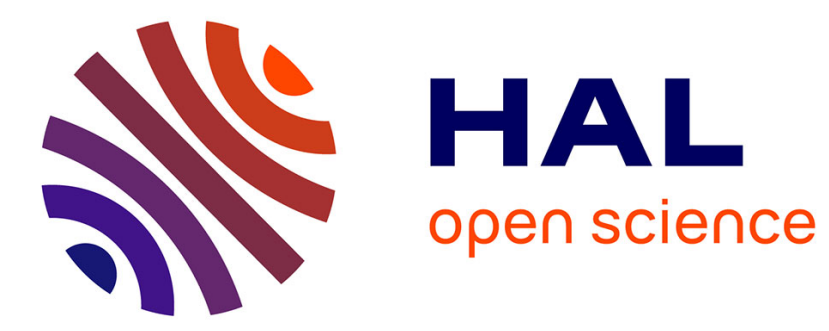

\title{
Trace level nitrite sensitized photolysis of the antimicrobial agents parachlormetaxylenol and chlorophene in water
}

Yueyue Li, Hao Qin, Yunong Li, Junhe Lu, Lei Zhou, J. M. Chovelon, Yuefei $\mathrm{Ji}$

\section{To cite this version:}

Yueyue Li, Hao Qin, Yunong Li, Junhe Lu, Lei Zhou, et al.. Trace level nitrite sensitized photolysis of the antimicrobial agents parachlormetaxylenol and chlorophene in water. Water Research, 2021, 200, 10.1016/j.watres.2021.117275 . hal-03289847

\section{HAL Id: hal-03289847 https://hal.science/hal-03289847}

Submitted on 6 Oct 2021

HAL is a multi-disciplinary open access archive for the deposit and dissemination of scientific research documents, whether they are published or not. The documents may come from teaching and research institutions in France or abroad, or from public or private research centers.
L'archive ouverte pluridisciplinaire HAL, est destinée au dépôt et à la diffusion de documents scientifiques de niveau recherche, publiés ou non, émanant des établissements d'enseignement et de recherche français ou étrangers, des laboratoires publics ou privés. 


\title{
Trace level nitrite sensitized photolysis of the antimicrobial agents parachlormetaxylenol and chlorophene in water
}

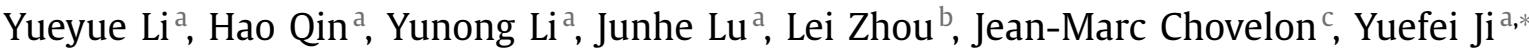 \\ ${ }^{a}$ College of Resources and Environmental Sciences, Nanjing Agricultural University, Nanjing 210095, China \\ ${ }^{\mathrm{b}}$ School of Resources and Environmental Engineering, East China University of Science and Technology, Shanghai 200237, China \\ ${ }^{\mathrm{c}}$ Univ Lyon, Université Claude Bernard Lyon 1, CNRS, IRCELYON, F-69626, Villeurbanne, France
}

Nitrite $\left(\mathrm{NO}_{2}{ }^{-}\right)$-sensitized photolysis plays an important role in the attenuation of effluent-derived trace organic contaminants (e.g., anilines, phenolic compounds, etc.) in surface waters. However, the kinetics, mechanisms, and influencing factors of photolysis of many emerging contaminants sensitized by $\mathrm{NO}_{2}{ }^{-}$still remain largely unknown. Herein, we report that $\mathrm{NO}_{2}{ }^{-}$-sensitized photolysis of the antimicrobial agents parachlormetaxylenol (PCMX) and chlorophene (CP) in aqueous solution under ultraviolet $365 \mathrm{~nm}\left(\mathrm{UV}_{365}\right)$ radiation. A nonlinear increase in photolysis rate constants of PCMX and CP was observed with increasing $\mathrm{NO}_{2}{ }^{-}$concentration. Radical quenching studies and kinetic modeling revealed that hydroxyl radical $(\mathrm{HO} \bullet)$ and nitrogen dioxide radicals $\left(\mathrm{NO}_{2}{ }^{\bullet}\right)$ contributed dominantly to the removal of PCMX and CP. Solid phase extraction (SPE) combined with high resolution-mass spectrometry (HRMS) analysis identified a series of intermediate products including hydroxylated, nitrated, nitrosated, and dimerized derivatives. Experiments with isotopically labelled nitrite $\left({ }^{15} \mathrm{NO}_{2}{ }^{-}\right)$showed that the nitro- and nitroso-substituents of intermediate products were derived from the nitrite nitrogen. Based on the identified products and theoretical computations, the mechanisms and pathways of $\mathrm{NO}_{2}{ }^{-}$-sensitized photolysis of PCMX and CP are elucidated. Deoxygenation partially inhibited the formation of 4-chloro-3,5dimethyl-2-nitrophenol (nitro-PCMX) while the presence of $\mathrm{HO}$ - scavenger such as isopropanol ( $i$-PrOH) suppressed the further transformation of nitro-PCMX. The presence of Mississippi River natural organic matter (MRNOM) inhibited the removal of PCMX and CP, likely due to light screening and radical quenching. However, appreciable degradation of PCMX and CP was still observed in wastewater and wetland water matrices. Results of this study shed some light on the transformation and fate of PCMX and CP in $\mathrm{NO}_{2}{ }^{-}$-rich wastewater effluents or effluent-impacted surface waters under solar radiation.

\section{Introduction}

$\mathrm{NO}_{2}{ }^{-}$is a well-known photosensitizer which has been implicated in the atmospheric and aqueous photochemistry (Minero et al., 2007). Under artificial or solar radiation, $\mathrm{NO}_{2}{ }^{-}$is capable of generating a series of reactive species, including hydroxyl radical $(\mathrm{HO} \bullet)$ and reactive nitrogen species (RNS) such as nitric oxide $\left(\mathrm{NO}{ }^{\bullet}\right)$ and nitrogen dioxide radicals $\left(\mathrm{NO}_{2}{ }^{\bullet}\right)$ (Reactions (1)-(3)) (Fischer and Warneck, 1996; Mack and Bolton, 1999).

$$
\begin{aligned}
& \mathrm{NO}_{2}{ }^{-}+h v \rightarrow \mathrm{NO} \cdot+\mathrm{O}^{-} \\
& \mathrm{O} \cdot^{-}+\mathrm{H}_{2} \mathrm{O} \rightarrow \mathrm{HO} \cdot+\mathrm{OH}^{-} \Phi_{\mathrm{HO} \cdot 365}=(4.5 \pm 1.0) \%
\end{aligned}
$$

* Corresponding Author. Yuefei Ji, College of Resources and Environmental Sciences, Nanjing Agricultural University, Nanjing 210095, China.

E-mail address: yuefeiji@njau.edu.cn (Y. Ji).
$\mathrm{NO}_{2}{ }^{-}+\mathrm{HO} \cdot \rightarrow \mathrm{NO}_{2} \cdot+\mathrm{OH}^{-} k=1.0 \times 10^{10} \mathrm{M}^{-1} \mathrm{~s}^{-1}$

These species play critical roles in the transformation and fate of organic contaminants in the environment (Pang et al., 2019; Scholes et al., 2019; Zhou et al., 2020). The concentrations of $\mathrm{NO}_{2}{ }^{-}$ in surface waters are generally low (e.g., 1 to 3 orders of magnitude lower than that of $\mathrm{NO}_{3}{ }^{-}$); however, $\mathrm{NO}_{2}^{-}$has a higher absorbance at ultraviolet A (UVA) range which makes it a potentially competitive photosensitizer (Vione et al., 2002;2003). While the photosensitization of $\mathrm{NO}_{2}{ }^{-}$has been less studied in aqueous photochemistry, there is evidence that the quantum yield of $\mathrm{HO}$ • by photolysis of $\mathrm{NO}_{2}^{-}$upon UV-visible radiation is comparative to that of $\mathrm{NO}_{3}{ }^{-}$(Xu et al., 2019). Therefore, the photosensitization of $\mathrm{NO}_{2}{ }^{-}$and its role in the transformation of environmental contaminants have been reevaluated recently (Pang et al., 2019; Scholes et al., 2019; Zhou et al., 2020). 
The occurrence of $\mathrm{NO}_{2}{ }^{-}$in the environment is mainly derived from the reduction of $\mathrm{NO}_{3}{ }^{-}$and, to a less extent, resulted from the degradation of dissolved organic matter (Kieber et al., 1999). A typical concentration of $\mathrm{NO}_{2}{ }^{-}$in surface waters is ca. $2 \times 10^{-6} \mathrm{M}$; however, higher concentrations are likely encountered in municipal wastewater treatment plant (WWTP) effluent due to the nitrification/denitrification processes of microbes (Kroupova et al., 2018). Therefore, when the effluent is released into the aquatic environment and exposed to solar radiation, $\mathrm{NO}_{2}{ }^{-}$is expected to influence the fate of effluent-derived contaminants as well as their ecotoxicological risks through photosensitization (Scholes et al., 2019; Zhou et al., 2020). For example, Scholes et al. (2019) proposed that $\mathrm{NO}_{2}{ }^{-}$-sensitized photolysis served as an important process responsible for the attenuation of sulfamethoxazole (SMX) in WWTP effluent. The generation of $\mathrm{HO} \bullet$ and RNS during $\mathrm{NO}_{2}{ }^{-}$photolysis induce the hydroxylation, nitration, and nitrosation reactions of organic compounds in aqueous solution (Shankar et al., 2007;2008; Nelieu et al., 2008). In particular, the nitration and nitrosation are undesirable due to the formation of mutagenic and carcinogenic nitro- and nitroso-derivatives (Kovacic and Somanathan, 2014). In addition, the photosensitizing efficiency of $\mathrm{NO}_{2}{ }^{-}$is closely related with the molecular structures of contaminants due to the electrophilic properties of HO and RNS (Zhou et al., 2020). In general, organic contaminants containing electron-rich moieties, such as anilino and phenolic groups, are susceptible to HO• and RNS attack (Pang et al., 2019; Scholes et al., 2019). However, except for a few compounds (e.g., SMX), the efficiencies and mechanisms of photolysis of many contaminants sensitized by $\mathrm{NO}_{2}{ }^{-}$have not been reported yet.

Parachlormetaxylenol (PCMX) and chlorophene (CP) are two antimicrobial agents widely applied in personal care products including hand sanitizer, soap, and shower gel. For example, hand sanitizers can contain PCMX with concentrations up to 0.18 $0.22 \%(\mathrm{~W} / \mathrm{W})$. After use, the antimicrobial agents enter municipal sewage mainly through hand washing and bathing (Juksu et al., 2019). The removal of antimicrobial agents by conventional municipal wastewater treatment systems is expected to be limited due to their bactericidal nature (Juksu et al., 2019). Consequently, high concentrations of antimicrobial agents have been detected in WWTP effluent (e.g., the concentration of PCMX reached 1.46 $5.59 \mu \mathrm{g} \mathrm{L}^{-1}$ in wastewater) (Li et al., 2020). The WWTP effluent, serving as a "hotpot" of pharmaceuticals and personal care products (PPCPs), is an important route through which antimicrobial agents are released into the environment (Michael et al., 2013). The occurrence of antimicrobial agents in the environment has been implicated in a range of endocrinological abnormalities in aquatic species (Sreevidya et al., 2018). These compounds can also be genotoxic and neurotoxic as demonstrated by PCMX and methylisothiazolinone (MIT) (Capkin et al., 2017). Abiotic transformation, such as $\mathrm{NO}_{2}{ }^{-}$-sensitized photolysis, is expected to be an important attenuation process affecting the fate of effluent-derived micropollutants such as antimicrobial agents. However, the kinetics, mechanisms, and influencing factors of photolysis of PCMX and CP sensitized by $\mathrm{NO}_{2}{ }^{-}$are unknown, which limit the accurate assessment of their environmental fate and risks.

In this contribution, we attempted to investigate the efficiencies and mechanisms of $\mathrm{NO}_{2}{ }^{-}$photosensitization in the removal of PCMX and CP in aqueous solution. Reactive species responsible for the degradation of PCMX and CP were discerned by radical quenching studies. The second-order rate constants between the antimicrobial agents and $\mathrm{HO} \bullet / \mathrm{NO}_{2}{ }^{\bullet}$ were determined either by competition kinetic method or by kinetic modeling. The transformation products of PCMX and CP were identified by high resolution-mass spectrometry (HR-MS) and the conversion of ni- trite nitrogen was traced by ${ }^{15} \mathrm{~N}$ isotope-labeling experiments. In particular, the toxic nitrated byproduct (i.e., nitro-PCMX) was quantified under different reaction conditions by high performance liquid chromatography (HPLC) with an authentic standard. Based on the identified products and theoretical computations, the mechanisms and pathways of $\mathrm{NO}_{2}{ }^{-}$-sensitized photolysis of PCMX and $\mathrm{CP}$ were elucidated. The effects of river water natural organic matter (NOM) and real waters on the removal of PCMX and CP were also evaluated. Results of this study may shed some light on the transformation and fate of PCMX and $\mathrm{CP}$ in $\mathrm{NO}_{2}{ }^{-}$-rich wastewater effluents or effluent-impacted surface waters under solar radiation.

\section{Materials and methods}

\subsection{Materials}

Chemicals, suppliers, and purities are provided in Text S1 of Supporting Information (SI). All other chemicals were of reagent grade or higher purity. Milli-Q water $(18 \mathrm{M} \Omega \mathrm{cm}$ ) was prepared from a Stakpure OmniaTap water purification system (Peculiar Instrument Technology, UK). All the stock solutions were prepared by dissolving chemicals into Milli-Q water and used within one week. Oasis hydrophilic-lipophilic balance (HLB) cartridges $(6 \mathrm{cc} / 200 \mathrm{mg}$, WAT106202) were purchased from Waters Corporation (Milford, MA, USA).

\subsection{Water samples}

Two surface waters (i.e., a wetland water and a wastewater) were used to investigate the effects of water matrices. The wetland water was sampled from a shallow macrophyte-dominated wetland in the Xiamafang Park near Nanjing Agricultural University. The wastewater was sampled from a local municipal wastewater treatment plant (Nanjing city, China). Both water samples were filtered through $0.22 \mu \mathrm{m}$ pore size cellulose acetate membranes prior to use. Characteristics of water samples including TOC, $\mathrm{Abs}_{365}$, alkalnity, nitrate, nitrite, and $\mathrm{pH}$ are provided in Table S1 of SI.

\subsection{Instrumentation}

Photolysis experiments were conducted in a multichannel collimated photoreactor (PCX50B Discover, Beijing, China) equipped with nine UV-LED lamps (5W) emitting predominantly $365 \mathrm{~nm}$ monochromatic light $\left(\mathrm{UV}_{365}\right)$. The LED lamps were mounted on a rotating dish to ensure that each reactor received uniform light radiation. The photoreactor adopted a bottom-up radiation mode. Incident photon irradiance was determined to be $1.27 \times 10^{-7}$ Einstein $\mathrm{cm}^{-2} \mathrm{~s}^{-1}$ by para-nitroanisole/pyridine (PNA/pyr) actinometry (Dulin and Mill, 1982). An integrated air-cooling system was equipped to maintain the temperature at $25^{\circ} \mathrm{C}$. A schematic diagram of the photoreactor is shown in Fig. S1 (SI).

The analytes were quantified by a Hitachi L-2000 high performance liquid chromatograph equipped with an L-2200 autosampler, an L-2130 binary pump, and an L-2455 diode array detector (DAD). Solid phase extractions (SPE) were conducted using a Supelco vacuum manifold (Sigma-Aldrich) with HLB cartridges. UVvisible absorption spectra were recorded by a Varian Cary 50 UVVis spectrophotometer (Varian, CA, USA) with $1 \mathrm{~cm}$ pathlength quartz cuvettes. Solution pH was measured by a PHS-3CW microprocessor $\mathrm{pH} / \mathrm{mV}$ meter (Bante instruments, Shanghai, China) using an E-201-C model composite glass electrode. $\mathrm{NO}_{2}{ }^{-}$and $\mathrm{NO}_{3}{ }^{-}$ ions were analyzed by an IC 6000 ion chromatograph (Wanyee, Anhui, China) equipped with a Shodex IC SI-52 4E column (250 mm length x $5 \mathrm{~mm}$, i.d.), a Shodex IC SI-92G pre-column, and a conductivity detector. 
Concentrations of PCMX, CP, nitro-PCMX, pCBA, and PNA were quantified by the L-2000 HPLC. Analytical separation was performed by an Agilent Zorbax Eclipse Plus C18 column $(5.0 \mu \mathrm{m}$ particle size, $250 \mathrm{~mm}$ length $\times 4.6 \mathrm{~mm}$, i.d.). Mobile phase was a combination of eluent $A$ (methanol with $0.1 \%$ formic acid) and eluent $B\left(\mathrm{H}_{2} \mathrm{O}\right.$ with $0.1 \%$ formic acid) at a flow rate of $1.0 \mathrm{~mL} \mathrm{~min}{ }^{-1}$. Detailed HPLC parameters can be found in Table S2 of SI. Quantification of analytes was based on multipoint standard calibration curves.

The intermediate products were identified by HPLC (Shimadzu, Kyoto, Japan) coupled with a Triple TOF $5600^{+}$mass spectrometer (LC-qTOF-MS/MS, AB Sciex, Boston, USA). Separation was accomplished using a Kinetex LC C18 column $(2.6 \mu \mathrm{m}, 100 \AA, 100$ $\mathrm{mm} \times 2.1 \mathrm{~mm}$, i.d.). Elution was performed at a flow rate of $0.3 \mathrm{~mL}$ min $^{-1}$ with $50 \%$ methanol (eluent A) and 50\% Milli-Q water (eluent B), employing an isocratic gradient. Sample injection volume was 2 $\mu \mathrm{L}$. Mass analyses were conducted in negative mode using an electrospray ionization (ESI) source. Instrumental parameters were as follows: ionspray voltage floating of $5500 \mathrm{~V}$; source temperature of $550^{\circ} \mathrm{C}$; gas I and gas II of $65 \mathrm{psi}$; curtain gas of 35 psi. Mass spectrometric data were collected in TOF MS full scan mode over a mass range of $50-800 \mathrm{~m} / \mathrm{z}$, and MS/MS scan mode (scan range of $50-800 \mathrm{~m} / \mathrm{z}$ ) was triggered by information-dependent acquisition (IDA) workflow at the same time. The MS/MS analyses were conducted in negative ion mode. Declustering potential, collision energy, and collision energy spread were $-80 \mathrm{~V},-30 \mathrm{eV}$, and $10 \mathrm{eV}$, respectively.

\subsection{Photolysis experiments}

The photolysis experiments were conducted in a series of cylindrical flat-bottomed quartz tubes $(31 \mathrm{~mm}$ i.d., $78 \mathrm{~mm}$ height, 59 $\mathrm{mL}$ volume). $50 \mathrm{~mL}$ solutions containing $20 \mu \mathrm{M}$ PCMX/CP and certain amounts of $\mathrm{NO}_{2}{ }^{-}(2$ to $100 \mu \mathrm{M})$ were transferred into the tubes. The solutions were buffered by $1 \mathrm{mM}$ phosphate $(\mathrm{pH} 7.0)$ to represent circumneutral $\mathrm{pH}$.

The photoreactor was turned on for 15 min for stabilization, and the tubes were then put into the photoreactor for radiation. Dark controls (wrapped with aluminum foil) and direct photolysis (in the absence of $\mathrm{NO}_{2}^{-}$) were run concurrently. In some experiments, excess scavengers (i.e., $i$-PrOH and TBA) were spiked into solutions prior to photolysis to discern the contribution of $\mathrm{HO} \bullet$ and RNS. The effects of $\mathrm{O}_{2}$ were explored by purging purified $\mathrm{N}_{2}$ into solutions over radiation to achieve anaerobic conditions. Different concentrations of MRNOM were added into solutions to evaluate the effects of river water NOM. The photolysis experiments were also carried out in wetland water and wastewater amended with $20 \mu \mathrm{M} \mathrm{PCMX} / \mathrm{CP}$ and $100 \mu \mathrm{M} \mathrm{NO}_{2}{ }^{-}$. Aliquots $(1 \mathrm{~mL})$ were withdrawn at predetermined time intervals and transferred to $1.5 \mathrm{~mL}$ amber HPLC vials. Samples were refrigerated at $4{ }^{\circ} \mathrm{C}$ and analyzed by HPLC within $24 \mathrm{~h}$. All experiments were carried out in duplicates to assure accurate data acquisition and error bars in figures represent standard deviations.

\subsection{Isolation and identification of intermediate products}

To identify intermediate products, two reaction solutions (50 mL, pH 7.0 buffer) containing $20 \mu \mathrm{M} \mathrm{PCMX/CP} \mathrm{and} 100 \mu \mathrm{M}$ $\mathrm{NO}_{2}{ }^{-}$were freshly prepared and then put into the photoreactor for radiation. Specifically, a mixture of $50 \%{ }^{14} \mathrm{NO}_{2}{ }^{-}+50 \%{ }^{15} \mathrm{NO}_{2}{ }^{-}$ was also used as photosensitizer to trace whether the nitroso- and nitro- substituents of intermediate products were derived from nitrite nitrogen (Kolkman et al., 2015). After 120 min of radiation, the photolytic solutions were withdrawn and then subjected to SPE enrichment using HLB cartridges. Detailed procedures of SPE can be found in our previous studies (Ji et al., 2018). The SPE-concentrated samples were analyzed by the high resolution-mass spectrometry (LC-qTOF-MS/MS) for identification of intermediate products.

\subsection{Determination of second-order rate constants between $\mathrm{HO}$ and $P C M X / C P$}

Second-order rate constants for reactions of HO• with PCMX/CP were determined by competition kinetic method in a $\mathrm{UV} / \mathrm{H}_{2} \mathrm{O}_{2}$ system (Baeza and Knappe, 2011). HO• is known as the sole free radical generated in the $\mathrm{UV} / \mathrm{H}_{2} \mathrm{O}_{2}$ system (Miklos et al., 2018). Detailed experimental procedures can be found in Text S2 of SI. The secondorder rate constants between $\mathrm{HO} \bullet$ and $\mathrm{PCMX} / \mathrm{CP}$ are calculated by the following equation (Fig. S2, SI):

$k_{\mathrm{HO} \cdot \mathrm{AA}}=\frac{\ln \left([\mathrm{AA}]_{\mathrm{t}} /[\mathrm{AA}]_{0}\right)}{\ln \left([p \mathrm{CBA}]_{\mathrm{t}} /[p \mathrm{CBA}]_{0}\right)} k_{\mathrm{HO} \cdot p \mathrm{CBA}}$

where $[A A]_{t}$ and $[A A]_{0}$ are the concentrations of the antimicrobial agents at time $t$ and zero, respectively; $[p C B A]_{t}$ and $[p C B A]_{0}$ are the concentrations of para-chlorobenzoic acid at time $t$ and zero, respectively; $k_{\mathrm{HO}} \bullet, \mathrm{AA}$ and $k_{\mathrm{HO}} \bullet$, $\mathrm{PCBA}$ are the second-order rate constants for $\mathrm{HO}$ - reactions with the antimicrobial agents and $p C B A$, respectively.

\subsection{Computational study}

In the present study, frontier electron densities (FEDs) of highest occupied molecular orbital (HOMO) and lowest unoccupied molecular orbital (LUMO) were computed using a Guassian 09 software package at B3LYP/6-311+G* level. As reported, the values of 2 FED $^{2}$ Hомо can be used to predict the reactive sites susceptible for electron transfer reaction, while the values of $\mathrm{FED}^{2}{ }_{\mathrm{HOMO}}+$ $\mathrm{FED}^{2}$ LUMO can be used to predict the sites susceptible to electrophilic radical addition (Qu et al., 2015; Zeng et al., 2016).

\section{Results and discussion}

\subsection{Reaction kinetics}

Direct photolysis of PCMX and $\mathrm{CP}$ was not observed under $\mathrm{UV}_{365}$ radiation (data not shown), consistent with the fact that the antimicrobial agents have no absorbance at $365 \mathrm{~nm}$ (Fig. S3, SI). Under circumneutral condition ( $\mathrm{pH} 7.0$ ), PCMX and CP were also found to be stable in the dark in the presence of $\mathrm{NO}_{2}{ }^{-}$ (dark control, data not shown). This is reasonable because $\mathrm{NO}_{2}{ }^{-}$induced dark reactions generally proceed through electrophilic aromatic substitutions $\left(\mathrm{S}_{\mathrm{E}} \mathrm{Ar}\right)$, which require a strongly acidic condition to generate nitrating/nitrosating agents such as nitrosonium ion $\left(\mathrm{NO}^{+}\right)$(Patnaik and Khoury, 2004; Kroflič et al., 2018). Exposure of PCMX and CP solutions to $\mathrm{UV}_{365}$ radiation in the presence of trace level $\mathrm{NO}_{2}^{-}(2-100 \mu \mathrm{M})$ resulted in rapid consumption of these antimicrobial agents (Fig. S4, SI), suggesting that reactive species resulted from $\mathrm{NO}_{2}{ }^{-}$photolysis were responsible for their removal. The degradation of PCMX obeyed pseudo-first-order reaction kinetics. The observed pseudo-first-order rate constant $\left(k_{\mathrm{obs}}\right)$, which was obtained by plotting $-\ln \left([\mathrm{PCMX}]_{\mathrm{t}} /[\mathrm{PCMX}]_{0}\right)$ as a function of irradiation time $t$, increased by a factor of 18.6 (i.e., 0.15 $2.79 \times 10^{-4} \mathrm{~s}^{-1}$ with half-life times $\left.12.83-0.69 \mathrm{~h}\right)$ as the $\mathrm{NO}_{2}{ }^{-}$ concentration was elevated from 2 to $100 \mu \mathrm{M}$ (Fig. 1).

A similar increment was also observed in $\mathrm{NO}_{2}{ }^{-}$-sensitized photolysis of $\mathrm{CP}$, with $k_{\text {obs }}$ value being increased by 20.9 -fold (i.e., 0.13 - $2.61 \times 10^{-4} \mathrm{~s}^{-1}$ with half-life times 15.4 - $0.74 \mathrm{~h}$ ) (Fig. 1). Intriguingly, the observed $k_{\text {obs }}$ value did not increased proportionally with the concentration of $\mathrm{NO}_{2}{ }^{-}$. The lack of a linear relationship between $k_{\text {obs }}$ and $\mathrm{NO}_{2}{ }^{-}$concentration is possibly due to the scavenging of $\mathrm{HO} \cdot$ by excess $\mathrm{NO}_{2}^{-}$(Shankar et al., 2007; Chen et al., 2015). Because $\mathrm{NO}_{2}{ }^{-}$reacts with $\mathrm{HO} \bullet$ at a diffusion-controlled rate 


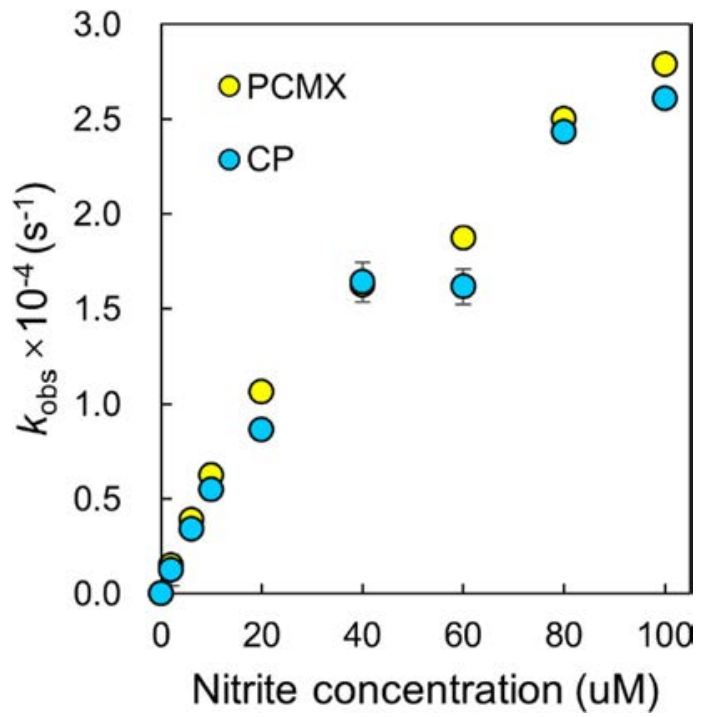

Fig. 1. The observed pseudo-first-order rate constant $\left(k_{\text {obs }}\right)$ of photolysis of $(\bullet)$ PCMX and $(\bullet) \mathrm{CP}$ sensitized by $\mathrm{NO}_{2}^{-}$with varying concentrations. Experimental conditions: $20 \mu \mathrm{M}$ PCMX or $\mathrm{CP}, 0-100 \mu \mathrm{M} \mathrm{NO}_{2}{ }^{-}, 1 \mathrm{mM}$ phosphate buffer (pH 7.0). Error bars represent the standard deviations $(n=2)$.

$\left(1.0 \times 10^{10} \mathrm{M}^{-1} \mathrm{~s}^{-1}\right)$, excess $\mathrm{NO}_{2}{ }^{-}$can serve as a dominant sink of HO and, therefore, reduce the steady-state concentration of HO• (Reaction (3)) (Vione et al., 2001; García Einschlag et al., 2009).

Irradiation of aqueous $\mathrm{NO}_{2}^{-}$solution results in the generation of $\mathrm{NO}_{3}{ }^{-}$as an important inorganic product (De Laurentiis et al., 2015). Preliminary experiment revealed that upon $\mathrm{UV}_{365}$ radiation, $12.2 \%$ of $\mathrm{NO}_{2}{ }^{-}(101.8 \mu \mathrm{M})$ was stoichiometrically converted to $\mathrm{NO}_{3}{ }^{-}(12.4 \mu \mathrm{M})$ after $2 \mathrm{~h}$ of photolysis (Fig. S5, SI). In the presence of PCMX, the yield of $\mathrm{NO}_{3}{ }^{-}$was increased up to $25.8 \%$ corresponding to $25.8 \mu \mathrm{M}$. The increased formation of $\mathrm{NO}_{3}{ }^{-}$in the presence of organic compound during $\mathrm{NO}_{2}^{-}$photolysis has previously been reported and was ascribed to the enhanced generation of $\mathrm{O}_{2}{ }^{-}-$and NO• (De Laurentiis et al., 2015).

\subsection{Reactive species}

The involvement of HO• and RNS in the photolysis of PCMX and $\mathrm{CP}$ was probed by quenching studies using two scavengers, namely $i$-PrOH and TBA. While both alcohols react with $\mathrm{HO} \bullet$ at high second-order rate constants (i.e., $1.9 \times 10^{9}$ and $6.8 \times 10^{8} \mathrm{M}^{-1} \mathrm{~s}^{-1}$, respectively), they are known to be inert with RNS (Zhou et al., 2020) (see below). However, the quenching of HO• by scavengers can result in a decline of $\mathrm{NO}_{2}{ }^{\bullet}$ because it is mainly derived from $\mathrm{HO}$ - reaction with $\mathrm{NO}_{2}{ }^{-}$in $\mathrm{UV}_{365} / \mathrm{NO}_{2}{ }^{-}$system (Scholes et al., 2019).

The presence of $10 \mathrm{mM} i$-PrOH decreased the $k_{\mathrm{obs}}$ values of PCMX and CP by $82.7 \%$ and $84.7 \%$, respectively (Fig. S6, SI). In the case of $10 \mathrm{mM}$ TBA as scavenger, the $k_{\text {obs }}$ values reduced by $69.1 \%$ and $66.7 \%$, respectively. The greater inhibitory effect of $i$-PrOH relative to TBA is in good agreement with their reactivities with HO• (Scholes et al., 2019). Kinetic calculations suggested that the addition of $10 \mathrm{mM} i$-PrOH/TBA quenched $96 \% / 84 \%$ of $\mathrm{HO} \bullet$, which in turn led to an $80 \% / 60 \%$ decrease in $\mathrm{NO}_{2}{ }^{\bullet}$ (see Table $\mathrm{S} 3$ and detailed calculations in Text S3, SI). Therefore, the above results highlight the important roles of $\mathrm{HO} \bullet$ and $\mathrm{NO}_{2}{ }^{-}$in $\mathrm{NO}_{2}{ }^{-}$-sensitized photolysis of PCMX and CP, which are consistent with various hydroxylated and nitrated products identified by HR-MS (vide infra). The second-order rate constants for reactions of $\mathrm{HO}$ - with $\mathrm{PCMX} / \mathrm{CP}$ were determined to be $2.74 \times 10^{9}$ and $6.94 \times 10^{9} \mathrm{M}^{-1} \mathrm{~s}^{-1}$, respectively, by competition kinetic method (Text S2 and Fig. S2, SI). These values approach diffusion-controlled limit in water (i.e.,
$7.4 \times 10^{9} \mathrm{M}^{-1} \mathrm{~s}^{-1}$ ), suggesting the high reactivities of antimicrobial agents with $\mathrm{HO} \bullet$. The observation that the removal of antimicrobial agents was not completely inhibited (e.g., for PCMX, the $k_{\text {obs }}$ values were $3.18-0.55 \times 10^{-4} \mathrm{~s}^{-1}$ and the removal percentages were $92.64-32.49 \%$ ) in the presence of excess scavengers implies that other reactive species (e.g., $\mathrm{NO}^{\bullet}, \mathrm{N}_{2} \mathrm{O}_{3}, \mathrm{ONOO}^{-} / \mathrm{ONOOH}$, etc.) also contributed to the degradation. However, these species are not expected to be important in the removal of antimicrobial agents due to their weaker redox potential (Xu et al., 2019).

Considering that $\mathrm{HO} \bullet$ and $\mathrm{NO}_{2}{ }^{\bullet}$ are dominant reactive species in $\mathrm{NO}_{2}{ }^{-}$-sensitized photolysis of antimicrobial agents, the transformation rate contributed by $\mathrm{NO}_{2}{ }^{\bullet}$ can be evaluated by the following equation (Scholes et al., 2019):

$k_{\mathrm{NO}_{2}}=k_{\mathrm{obs}}-k_{\mathrm{HO} .}=k_{\mathrm{obs}}-k_{\mathrm{HO}, \mathrm{AA}}[\mathrm{HO} \cdot]_{\mathrm{sS}}$

where $k_{\mathrm{HO}}$ is the transformation rate caused by $\mathrm{HO} \bullet$ reaction; $k_{\mathrm{HO}}, \mathrm{AA}$ is the second-order rate constant between $\mathrm{HO} \bullet$ and the antimicrobial agent; and $[\mathrm{HO} \bullet]_{s s}$ is the steady-state concentration of $\mathrm{HO} \bullet$. The $k_{\mathrm{NO} 2}$ • value can be calculated by the following equation:

$k_{\mathrm{NO}_{2}}=k_{\mathrm{NO}_{2} \cdot, \mathrm{AA}}\left[\mathrm{NO}_{2} \cdot\right]_{\mathrm{sS}}$

where $k_{\mathrm{NO} 2} \bullet$,AA is the second-order rate constant between $\mathrm{NO}_{2}{ }^{\bullet}$ and the antimicrobial agent; and $\left[\mathrm{NO}_{2}{ }^{\circ}\right]_{\text {ss }}$ is the steady-state concentration of $\mathrm{NO}_{2}{ }^{\bullet}$. It is assumed that in $\mathrm{UV}_{365} / \mathrm{NO}_{2}{ }^{-}$system, $\mathrm{NO}_{2}{ }^{\bullet}$ is generated predominantly by $\mathrm{HO} \cdot$ reaction with $\mathrm{NO}_{2}{ }^{-}$, and the dominant fate of $\mathrm{NO}_{2}{ }^{\bullet}$ is dimerization followed by hydrolysis (Reactions (4) and (5)) (Minero et al., 2007).

$2 \mathrm{NO}_{2} \leftrightarrow \mathrm{N}_{2} \mathrm{O}_{4}, k_{1}=4.5 \times 10^{8} \mathrm{M}^{-1} \mathrm{~s}^{-1} ; k_{-1}=6.9 \times 10^{3} \mathrm{~s}^{-1}$

$\mathrm{N}_{2} \mathrm{O}_{4}+\mathrm{H}_{2} \mathrm{O} \rightarrow \mathrm{NO}_{3}^{-}+\mathrm{NO}_{2}^{-}+\mathrm{H}^{+} ; k_{2}=1.0 \times 10^{3} \mathrm{~s}^{-1}$

Therefore, according to a steady-state approximation method, $[\mathrm{HO} \bullet]_{\mathrm{ss}}$ and $\left[\mathrm{NO}_{2}{ }^{\bullet}\right]_{\text {ss }}$ can be calculated by the following equations (see Text S4 of SI for detailed derivation):

$[\mathrm{HO} \cdot]_{\mathrm{SS}}=\frac{2.3 E_{\mathrm{p}}^{0} \varepsilon_{\mathrm{NO}_{2}^{-}} \Phi_{\mathrm{NO}_{2}^{-} \rightarrow \mathrm{HO} \cdot\left[\mathrm{NO}_{2}^{-}\right]}}{k_{\mathrm{HO} \cdot \mathrm{NO}_{2}^{-}}\left[\mathrm{NO}_{2}^{-}\right]+k_{\mathrm{HO} \cdot \mathrm{AA}}[\mathrm{AA}]}$

$\left[\mathrm{NO}_{2}\right]_{\mathrm{sS}}=\sqrt{\frac{k_{\mathrm{HO} \cdot \mathrm{NO}_{2}^{-}}\left(k_{-1}+k_{2}\right)[\mathrm{HO} \cdot]_{\mathrm{SS}}\left[\mathrm{NO}_{2}^{-}\right]}{2 k_{1} k_{2}}}$

where $E_{\mathrm{p}}^{0}$ is the incident photon irradiance; $\varepsilon_{\mathrm{NO}_{2}^{-}}$is the molar absorption coefficient of $\mathrm{NO}_{2}^{-}$at $365 \mathrm{~nm}$; and $\Phi_{\mathrm{NO}_{2}^{-} \rightarrow \mathrm{HO}}$. is the quantum yield of $\mathrm{HO} \bullet$ by $\mathrm{NO}_{2}^{-}$photolysis; $k_{1}, k_{-1}$, and $k_{2}$ are the rate constants of forward, reverse, and hydrolysis reactions of $\mathrm{N}_{2} \mathrm{O}_{4}$, respectively. We performed a linear regression of $k_{\mathrm{NO} 2} \bullet$ versus calculated $\left[\mathrm{NO}_{2}{ }^{\bullet}\right]_{\mathrm{SS}}$ and obtained $k_{\mathrm{NO} 2} \bullet$,AA values of $2.3 \times 10^{4}$ and $1.1 \times 10^{4} \mathrm{M}^{-1} \mathrm{~s}^{-1}$ for PCMX and CP, respectively (Fig. 2). The $k_{\mathrm{NO} 2} \bullet \mathrm{AA}$ value of PCMX is higher than those of other phenolic compounds reported in literature, e.g., $3.2 \times 10^{3} \mathrm{M}^{-1} \mathrm{~s}^{-1}$ for phenol and $1.1 \times 10^{4} \mathrm{M}^{-1} \mathrm{~s}^{-1}$ for 4-chlorophenol (Maddigapu et al., 2010), possibly due to the electron donating effect of methyl groups. Given that $\left[\mathrm{NO}_{2}{ }^{\bullet}\right]_{\text {ss }}$ in surface water is typically $10^{-11}-10^{-9} \mathrm{M}$ (Minero et al., 2007), the half-life times of PCMX and CP are deduced to be 8.4 - 836 and 17.5 - $1750 \mathrm{~h}$, respectively. This result implies that $\mathrm{NO}_{2}{ }^{\bullet}$ may play an important role in the attenuation of PCMX and $\mathrm{CP}$ in sunlit surface waters containing high concentrations of $\mathrm{NO}_{2}{ }^{-}$. Interestingly, the $k_{\mathrm{NO} 2} \bullet, \mathrm{AA}$ value of $\mathrm{CP}$ is exactly the same as that of 4-chlorophenol, implying that the benzyl moiety is inert with respect to $\mathrm{NO}_{2}{ }^{\bullet}$ reaction. This result corroborates the fact that $\mathrm{NO}_{2}{ }^{\bullet}$ is not as strong an electrophilic radical $\left(E^{\mathrm{o}}\left(\mathrm{NO}_{2}{ }^{\bullet} / \mathrm{NO}_{2}{ }^{-}\right)=1.04 \mathrm{~V}\right)$ and its reaction is regioselective (Vione et al., 2001). 


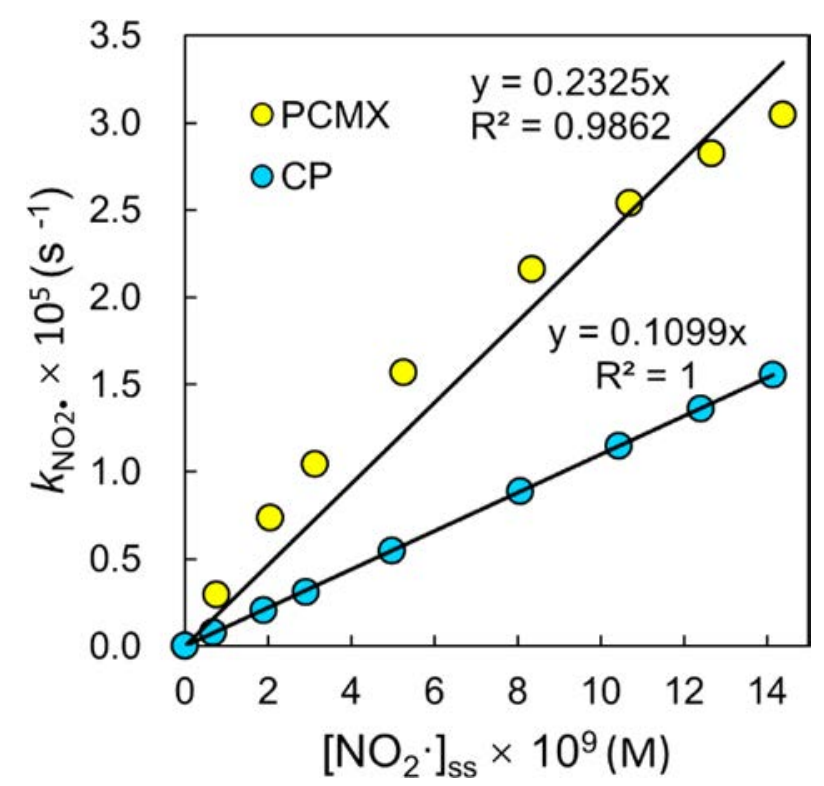

Fig. 2. Linear regression of $k_{\mathrm{NO} 2} \bullet$ versus calculated $\left[\mathrm{NO}_{2} \bullet\right]_{\mathrm{Ss}}$ to obtain $k_{\mathrm{NO} 2} \bullet$, AA values for $(\bullet) \operatorname{PCMX}\left(2.3 \times 10^{4} \mathrm{M}^{-1} \mathrm{~s}^{-1}\right)$ and $(\bullet) \mathrm{CP}\left(1.1 \times 10^{4} \mathrm{M}^{-1} \mathrm{~s}^{-1}\right)$. The value of $k_{\mathrm{NO} 2} \bullet$ was calculated by Eq. (2), and the value of $\left[\mathrm{NO}_{2} \bullet\right]_{\text {ss }}$ was calculated by Eqs. (4) and (5). Experimental conditions: $20 \mu \mathrm{M}$ PCMX or $\mathrm{CP}, 0-100 \mu \mathrm{M} \mathrm{NO}_{2}^{-}, 1$ $\mathrm{mM}$ phosphate buffer ( $\mathrm{pH} 7.0$ ).

\subsection{Intermediate products and transformation pathways}

The intermediate products generated in $\mathrm{NO}_{2}{ }^{-}$-sensitized photolysis of PCMX and CP were concentrated by SPE and then identified by HR-MS. The assignments of intermediate products were based on the following criteria: (i) the detected exact masses with error less than $5 \mathrm{ppm}$ of the theoretical exact masses, (ii) the fragmentation patterns of molecular ions, (iii) the characteristic isotope distribution endowed by the chloride atom, and (iv) comparison to the exact masses and retention times of authentic standards (commercially available). In particular, isotopically labeled nitrite $\left({ }^{15} \mathrm{NO}_{2}^{-}\right)$was used as a nitrogen source to trace if the nitrosoand nitro-substituents of intermediate products were derived from $\mathrm{NO}_{2}{ }^{-}$(Kolkman et al., 2015). Overall, a series of products including hydroxylated, nitrated, nitrosated, and dimerized derivatives were temporarily identified (Table S4 and S5, SI), providing further evidence that $\mathrm{HO} \bullet \mathrm{NO}_{2}{ }^{\circ}$, and $\mathrm{NO}^{\bullet}$ were involved in the $\mathrm{NO}_{2}{ }^{-}$sensitized photolysis of PCMX and CP (Ge et al., 2019).

As expected, $\mathrm{HO} \cdot$ produced by photolysis of $\mathrm{NO}_{2}{ }^{-}$upon $\mathrm{UV}_{365}$ radiation can lead to the hydroxylation of PCMX. Interestingly, two isomers of monohydroxylated PCMX (P-1) were identified by HRMS, implying that hydroxylation likely occurred at different positions of PCMX molecule (i.e., the aromatic ring or the methyl side chain). Further support in favor of hydroxylation at different positions was obtained by examining the fragmentation patterns provided by HR-MS (Fig. S7, SI). The lack of fragment with $m / z 79.0595$ derived from consecutive loss of $28 \mathrm{Da}(-\mathrm{CO})$ possibly suggested that the hydroxylation occurred at the methyl group. In addition, computational studies revealed the high $\mathrm{FED}^{2}{ }_{\mathrm{HOMO}}+\mathrm{FED}^{2}{ }_{\mathrm{LOMO}}$ values of the unsubstituted positions (C2 and $\mathrm{C} 4$ ), indicating that the ortho-sites with respect to the phenolic hydroxyl group are susceptible to the electrophilic substitution of HO• (Table S6, SI). While the $\mathrm{FED}^{2}{ }_{\text {Hомо }}+\mathrm{FED}^{2}$ Lомо values of the methyl-substituted positions ( $\mathrm{C} 1$ and $\mathrm{C} 5$ ) are also high, these positions are unlikely to be hydroxylated due to the steric hindrance of the bulky methyl groups that will reduce the accessibility of HO• (Chen et al., 2015). The addition of $\mathrm{HO}$ - at aromatic ring is known to generate a hydroxycyclohexadienyl (HCHD) radical, which undergoes further $\mathrm{O}_{2}$ addition and hydroxyl peroxide radical $\left(\mathrm{HO}_{2}{ }^{\bullet}\right)$ elimination, giving rise to a hydroxylated product (Scheme 1 of Fig. 3) (Mvula et al., 2001). In the case of side chain substitution with HO• attacking one of the methyl groups, the reaction is likely initiated by $\mathrm{H}$ abstraction, resulting in the formation of a carbon-centered benzyl radical that combines with another $\mathrm{HO} \bullet$ to generate a carbinol product ( $\mathrm{Ph}-\mathrm{CH}_{2}-\mathrm{OH}$ ) (Scheme 2 of Fig. 3) (Pignatello et al., 2006). It has been reported that the $\mathrm{H}$-abstraction of alkyl side chain by $\mathrm{HO} \bullet$ attack generally occurs at a rate constant much slower than that of ring addition (Gligorovski et al., 2015). In addition, the methyl positions ( $\mathrm{C} 7$ and $\mathrm{C} 8$ ) possess much lower $\mathrm{FED}^{2}{ }_{\mathrm{HOMO}}+$ $\mathrm{FED}^{2}$ LOMO values $(0.0026$ and 0.0021$)$, suggesting that the ring hydroxylation is more favorable than the methyl group hydroxylation. The initial hydroxylation will increase the electron density of the aromatic ring, thus favoring further hydroxylation under the attack of HO•. Therefore, the consecutive attack of $\mathrm{HO} \bullet$ can lead to the formation of dihydroxylated (P-2) and trihydroxylated products (P3). It should be emphasized that unequivocal structural assignment of the hydroxylated (mono-, di-, and tri-) products is impossible at the current stage due to the lack of reference standards, and additional spectroscopic analyses such as nuclear magnetic resonance (NMR) are necessary to ascertain the exact hydroxylated positions. Polyhydroxylated products are rich in electron density and thus are susceptible to ring-opening, giving rise to various carboxylic acids and aldehydes (Yang et al., 2020). It should further be noted that SPE used to concentrate photoproducts may result in the loss of highly polar compounds, in particular those low-molecular-weight compounds such as aromatic ring cleaving products. Therefore, additional experiments with elevated contaminant concentrations (which do not require a preconcentration step) are essential to determine whether any additional products are present.

$\mathrm{NO}_{2}{ }^{\bullet}$ generated from $\mathrm{UV}_{365} / \mathrm{NO}_{2}{ }^{-}$is capable of nitrating parent compound, as evidenced by the detection of 4-chloro3,5-dimethyl-2-nitrophenol (nitro-PCMX) (P-4, exact mass $\mathrm{m} / \mathrm{z}$ $200.0122 / 202.0099$ with an isotopic abundance ratio of 3:1 endowed by the chlorine atom, $\Delta \mathrm{ppm} 0.9$ ). This nitro-derivative was unequivocally confirmed by ${ }^{15} \mathrm{~N}$ isotope-labeling experiments (Fig. 4) as well as by comparison with an authentic standard (CAS 54852-90-0). When $50 \%{ }^{14} \mathrm{NO}_{2}{ }^{-}+50 \%{ }^{15} \mathrm{NO}_{2}{ }^{-}$was used as nitrogen source, HR-MS spectrum revealed the formation of ${ }^{15} \mathrm{NO}_{2}$ PCMX (exact mass $m / z$ 201.0096/203.0063; $\Delta$ ppm 0.9) with molecular weight 1 Da greater than that of ${ }^{14} \mathrm{NO}_{2}$-PCMX, indicating that the nitro group of nitro-PCMX was derived from the $\mathrm{NO}_{2}^{-}$nitrogen (Kolkman et al., 2015). $\mathrm{NO}_{2}{ }^{-}$-induced photonitration of aryl compounds has been widely reported (Machado and Boule, 1995; Vione et al., 2004;2005; Calza et al., 2012; Shankar et al., 2007;2008; Nelieu et al., 2008; Chen et al., 2015). In general, the nitration of phenolic compounds by $\mathrm{NO}_{2}{ }^{\bullet}$ is known to proceed through two-stage reactions (Barletta et al., 2000; Barzaghi and Herrmann, 2002). The initial reaction involves $\mathrm{H}$-abstraction between $\mathrm{NO}_{2}{ }^{\bullet}$ and substituted phenols (Shenghur et al., 2014). In the case of PCMX containing 4-chlorophenol moiety, the reaction is likely initiated by abstraction of phenolic hydrogen, leading to the formation of a phenoxyl radical and HONO, as evidenced by DFT calculations (Bedini et al., 2012; Ji et al., 2019b; Zhao et al., 2020). The phenoxyl radical can be stabilized via delocalization of its unpaired electron to ortho- or para-positions through resonance. Subsequently, the combination of phenoxyl radical with another $\mathrm{NO}_{2}{ }^{\bullet}$ generates 4-chloro-2-nitrocyclohexa2,5-dienone (Clewley et al., 1989). Such dienone is known to be unstable and undergoes rearrangement with the assistance of a $\mathrm{H}_{2} \mathrm{O}$ molecule, resulting in the formation of nitro-derivative (Ji et al., 2017; Chen et al., 2020) (Scheme 3 of Fig. 3). Nitro-PCMX may also be generated by coupling reaction of $\mathrm{NO}_{2} \bullet$ with the $\mathrm{HO} \bullet-$ adduct (i.e., HCHD radical) followed by the elimination of a $\mathrm{H}_{2} \mathrm{O}$ molecule (Dzengel et al., 1999; Barzaghi and Herrmann, 2002). 


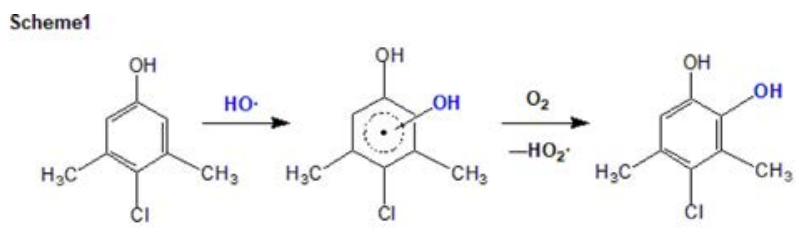

Scheme 2<smiles>Cc1cc(O)cc(C)c1Cl</smiles>

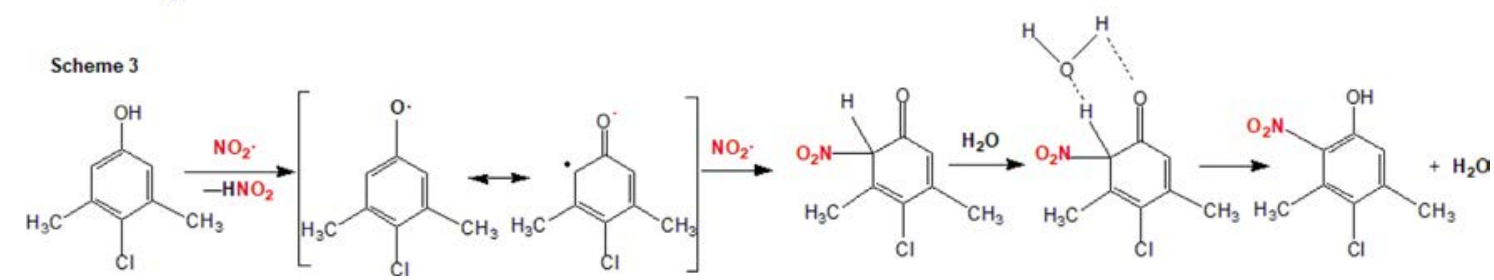

Fig. 3. Detailed mechanisms accounting for the formation of hydroxylated and nitrated byproducts during $\mathrm{NO}_{2}{ }^{-}-\mathrm{sensitized}$ photolysis of $\mathrm{PCMX}$.

Spectrum from 2.wiff (sample 1) - Sample002, Experiment 1, -TOF MS (50 - 800) from 7.607 to 7.639 min C8H8CINO3 -H

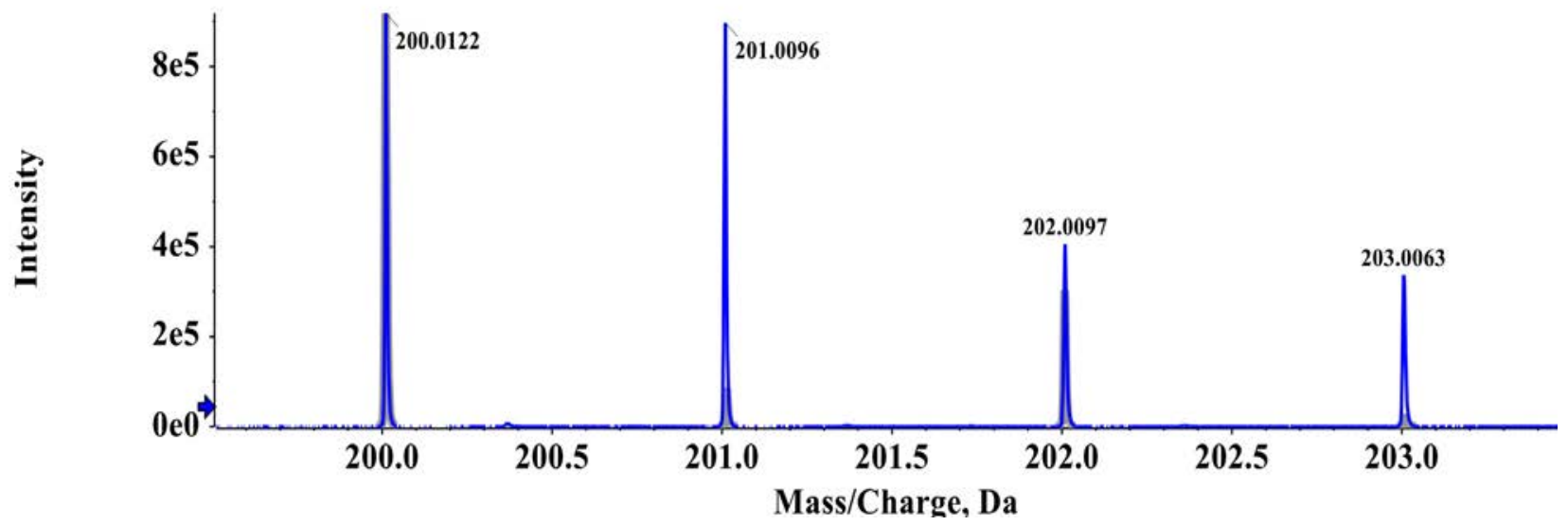

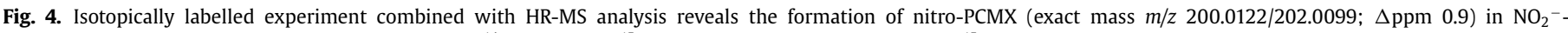

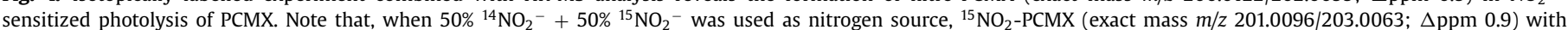

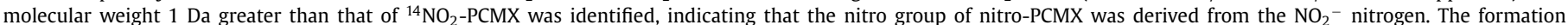
of nitro-PCMX was further confirmed by comparison with an authentic standard (CAS. CAS 54852-90-0) via HPLC analysis.

However, the HO•-adduct readily undergoes ring-opening in the presence of oxygen (Dzengel et al., 1999), which may inhibit the formation of nitrated byproducts. The coupling reaction between $\mathrm{NO}_{2}{ }^{\bullet}$ and the $\mathrm{HO} \bullet$-adduct is also expected to be less significant at high concentration of $\mathrm{NO}_{2}{ }^{-}$, because the steady-state concentration of $\mathrm{HO} \bullet$ is low due to the scavenging of $\mathrm{NO}_{2}{ }^{-}$(Vione et al., 2001; García Einschlag et al., 2009). Nitration can also be initiated by $\mathrm{H}$-abstraction from the methyl group by photochemically produced $\mathrm{HO} \bullet$ or other radicals. Such reaction is known to generate a benzyl radical (Elias et al., 2011). The addition of $\mathrm{NO}_{2}{ }^{\bullet}$ to the benzyl radical gives rise to a phenylnitromethane $\left(\mathrm{Ph}-\mathrm{CH}_{2}\right.$ $\mathrm{NO}_{2}$ ), as observed in the nitration of toluene in irradiated nitric solution (Elias et al., 2011). It is noteworthy that no dinitro- or polynitro-derivatives were detected in the present study. This result can be explained by the fact that the first nitro group can reduce the electron density of aromatic ring by resonance and induction and, therefore, decrease the reactivity of the molecule. How- ever, nitro-PCMX can undergo further hydroxylation via HO• attack to generate polyhydroxylated intermediates (P-5, P-6). These hydroxylated-nitrated-derivatives are also likely formed via nitration of (poly)hydroxylated PCMX (P-1, P-2), as described in Fig. 5.

Isotope-labeling experiment combined with HR-MS analysis also confirmed the generation of nitrosated product of PCMX (P7, exact mass $m / z 184.0174 / 186.0088, \Delta p p m ~ 1.6)$. Similar to nitration, the nitrosation is likely resulted from the coupling reaction of $\mathrm{NO}^{\bullet}$ with the resonance-stabilized radical or the benzyl radical. The former will lead to a ring-substituted product; while the latter will result in a benzaldehyde oxime by $\mathrm{NO}^{\bullet}$ addition followed with a rearrangement $\left(\mathrm{Ph}-\mathrm{CH}_{2}-\mathrm{NO} \rightarrow \mathrm{Ph}-\mathrm{CH}=\mathrm{NOH}\right.$ ) (Elias et al., 2011). However, nitroso-PCMX is also likely generated by nitrosation with $\mathrm{N}_{2} \mathrm{O}_{3}$, an important nitrosating agent that can be formed by coupling of $\mathrm{NO}^{\bullet}$ with $\mathrm{NO}_{2}{ }^{\bullet}$ in $\mathrm{UV}_{365} / \mathrm{NO}_{2}{ }^{-}$system (Vione et al., 2001). P-7 would have undergone further transformation during $\mathrm{NO}_{2}{ }^{-}$photolysis; however, our HR-MS analysis did not detect any 


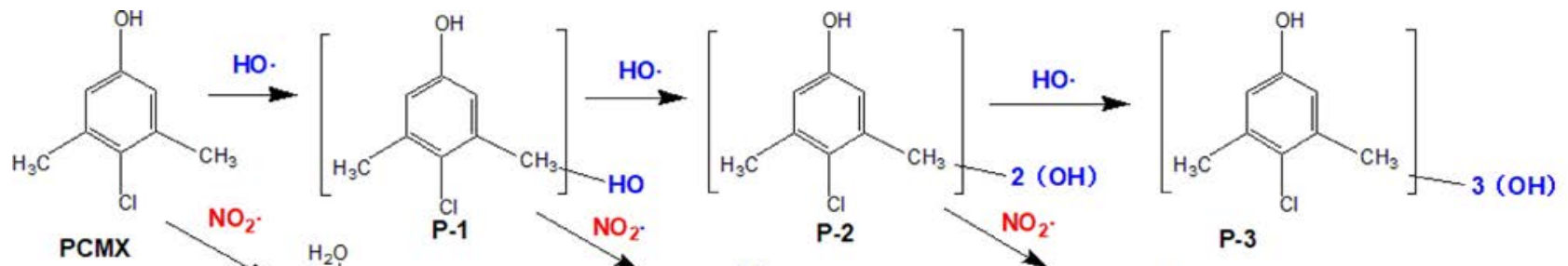

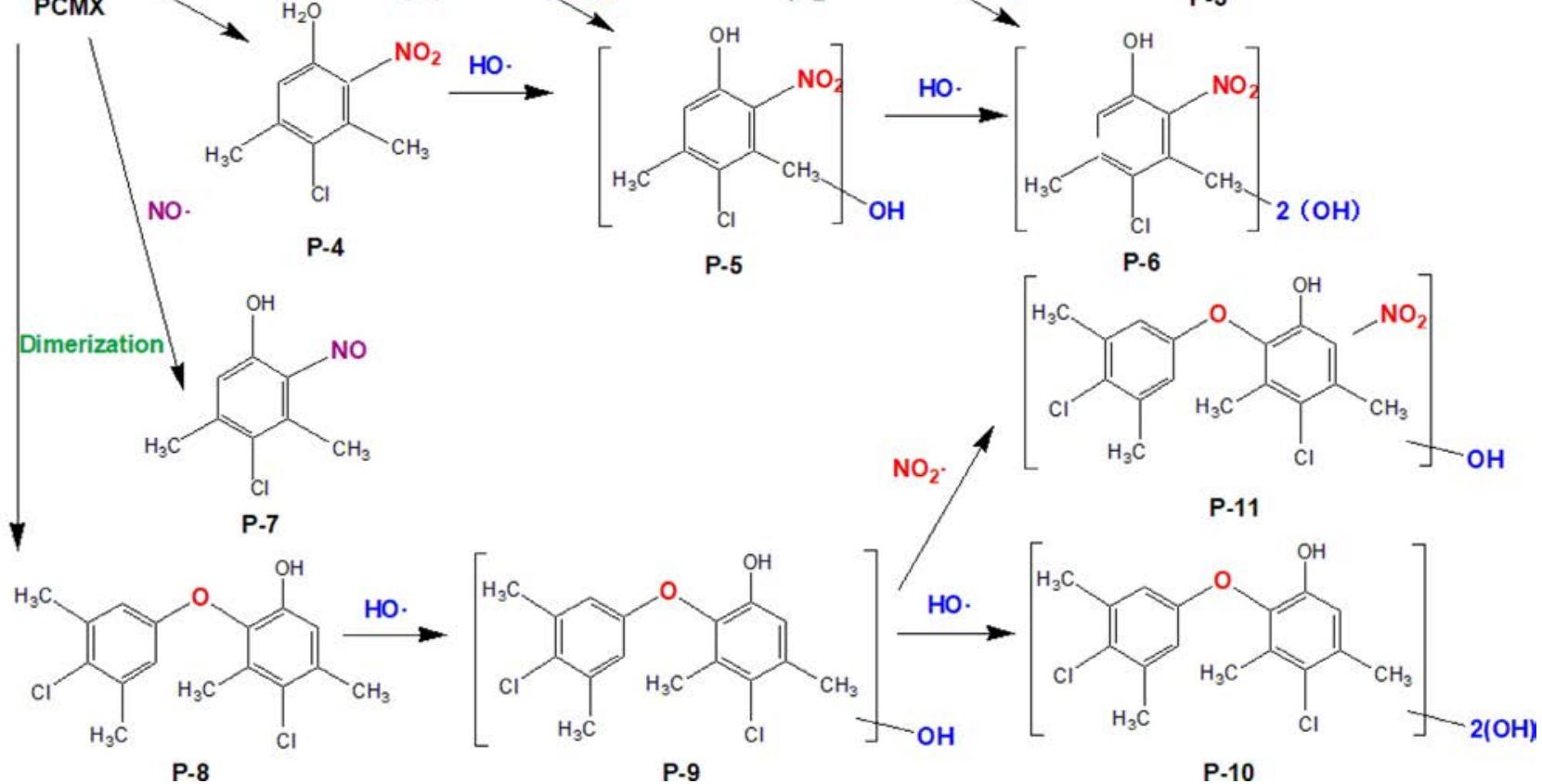

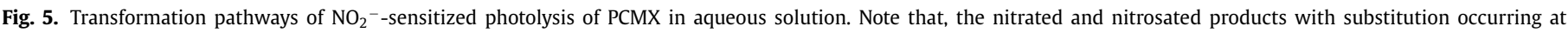
the methyl group were not showed in this figure for readability issues.

transformation products of P-7 (e.g., the dimer or hydroxylation products). While the reason is unclear, one possible explanation is that P-7 was quickly converted to the nitrated product P-4 in the presence of dissolved oxygen (Vione et al., 2001).

Interestingly, HR-MS analysis identified a dimer of PCMX (P8, exact mass $m / z$ 293.0584/295.0557/297.0530, $\Delta$ ppm 2.5), which might be originated from coupling reaction between phenoxyl radical and its resonance-stabilized radical (Ji et al., 2019a). The formation of dimer evidences the involvement of phenoxyl radicals as important precursors in $\mathrm{UV}_{365} / \mathrm{NO}_{2}{ }^{-}$system. It should be noted that dimerization consumes a fraction of phenoxyl radicals, which will diminish the nitration of PCMX. The dimer is likely subjected to further hydroxylation and/or nitration, leading to the formation of P-9, P-10, and P-11 (Fig. 5).

The transformation pathways of $\mathrm{CP}$ photolyzed in the presence of $\mathrm{NO}_{2}{ }^{-}$are illustrated in Fig. S8 of SI. Most notably, the photosensitization of $\mathrm{NO}_{2}{ }^{-}$resulted in the formation of nitrated $\mathrm{CP}$ (C-4), as confirmed by isotope-labeling experiments coupled with HR-MS analysis (Table S5 and Fig. S9, SI). The identification of $\mathbf{C}-4$ suggests that $\mathrm{NO}_{2}{ }^{\bullet}$ was also involved in the transformation of $\mathrm{CP}$, which is consistent with the results of radical quenching studies. Due to its electrophilic nature and regioselectivity (Bedini et al., 2012; Ji et al., 2019b), $\mathrm{NO}_{2}{ }^{\bullet}$ most likely attacks the 4-chlorophenol moiety of $\mathrm{CP}$ rather than the benzyl moiety. This hypothesis is justified by the computational study showing the higher electron density of chlorophenolic ring (Table S7, SI). Another piece of evidence is the kinetic result showing that both $\mathrm{CP}$ and 4-chlorophenol react with $\mathrm{NO}_{2}{ }^{\bullet}$ at the same rate constant (i.e., $1.1 \times 10^{4} \mathrm{M}^{-1} \mathrm{~s}^{-1}$ ) (Maddigapu et al., 2010). As mentioned previously, the $\mathrm{H}$-abstraction of $\mathrm{CP}$ induced by $\mathrm{NO}_{2}{ }^{\bullet}$ attack generates a phenoxyl radical that coupled with another $\mathrm{NO}_{2}{ }^{\bullet}$ to generate nitro-CP.
Both $\mathrm{CP}$ and nitro-CP can undergo further hydroxylation under the attack of $\mathrm{HO} \bullet$, giving rise to mono- (C-1 and C-5), di- (C-2 and (-6), and tri-hydroxylated derivatives (C-3 and C-7) sequentially. It should be noted that six mono-hydroxylated isomers were detected by extracted ion chromatograms (data not shown), suggesting that the attack of $\mathrm{HO} \bullet$ could occur at different positions of $\mathrm{CP}$ molecule. In order to determine the exact positions where HO• substituted, further analytical methods such as NMR are required.

While the nitrosated product of $\mathrm{CP}$ was not identified by HRMS, we cannot rule out the possibility that nitrosation occurred during $\mathrm{NO}_{2}{ }^{-}$-sensitized photolysis of $\mathrm{CP}$. The most reasonable explanation of this observation, as discussed above, is the quick transformation of nitroso-CP in the presence of dissolved oxygen (Vione et al., 2001). In addition, no dimeric products were detected, possibly due to the steric hindrance of the bulky benzyl moiety.

\subsection{Tracing nitro-PCMX}

As nitro-derivatives can be mutagenic and carcinogenic (Kovacic and Somanathan, 2014), their formation in $\mathrm{UV}_{365} / \mathrm{NO}_{2}{ }^{-}$ system should be scrutinized. In the present study, the formation of nitro-PCMX under different conditions was quantified because its authentic standard is commercially available. Irradiation of an aqueous solution containing $20 \mu \mathrm{M}$ PCMX and $100 \mu \mathrm{M} \mathrm{NO}_{2}{ }^{-}$ resulted in the quick formation of nitro-PCMX with its concentration reaching maximum at $2.5 \mathrm{~h}$ (3.27 $\mu \mathrm{M}, 16.4 \%$ yield) (Fig. 6). This product decreased appreciably thereafter and disappeared completely after $4 \mathrm{~h}$.

The evolution of nitro-PCMX was highly dependent on reaction conditions. Under anaerobic condition ( $\mathrm{N}_{2}$ purging), the formation rate of nitro-PCMX was lower than that observed in control ex- 


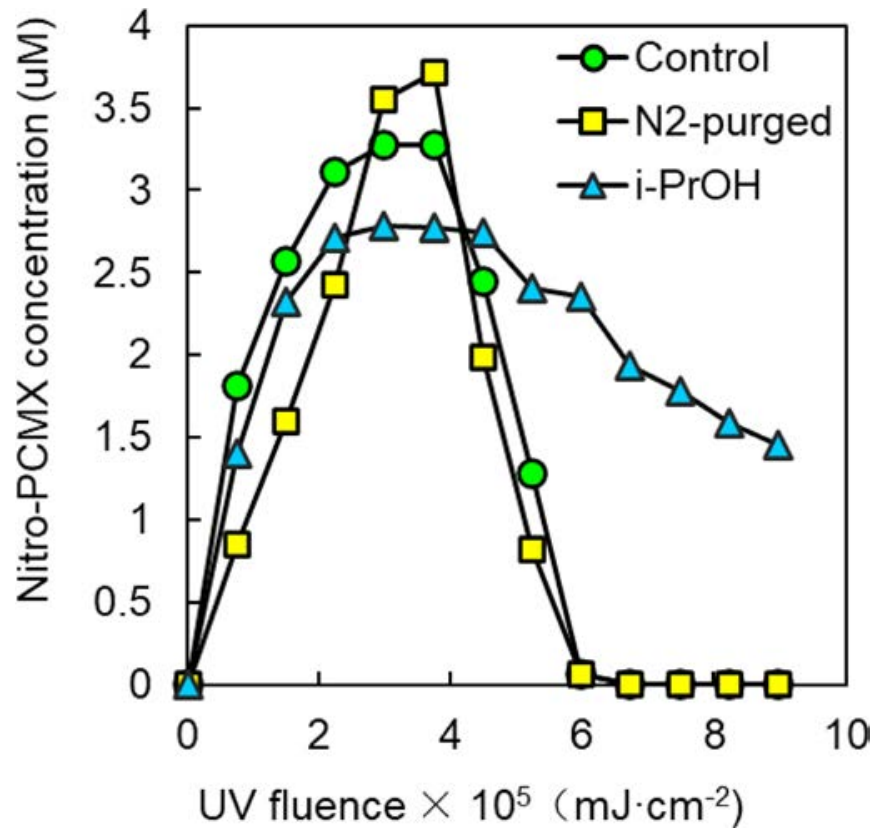

Fig. 6. Evolution profiles of nitro-PCMX during $\mathrm{NO}_{2}{ }^{-}$-sensitized photolysis of PCMX under different reaction conditions: $(\bullet)$ control, $(\boldsymbol{\square}) \mathrm{N}_{2}$-purging to remove dissolved oxygen, and $(\mathbf{\Lambda})$ in the presence of $10 \mathrm{mM} i-\mathrm{PrOH}$ as $\mathrm{HO} \bullet$ scavenger. Experimental conditions: $20 \mu \mathrm{M}$ PCMX, $100 \mu \mathrm{M} \mathrm{NO}_{2}^{-}, 1 \mathrm{mM}$ phosphorate buffer (pH 7.0).

periment (Fig. 6). This finding can be rationalized by two facts. (i) Deoxygenation blocked some pathways that otherwise led to the formation of $\mathrm{NO}_{2} \bullet$. It has been reported that $\mathrm{O}_{2}$ is conducive to the radical chain propagations of $\mathrm{NO}^{\bullet}$, which in turn favors the formation of $\mathrm{NO}_{2}{ }^{\bullet}$ (Reactions (4)-(10)). For example, $\mathrm{O}_{2}$ is necessary for the formation of $\mathrm{O}_{2}{ }^{\bullet-} / \mathrm{HO}_{2}{ }^{\bullet}$ that combine with $\mathrm{NO}^{\bullet}$ to produce $\mathrm{ONOO}^{-} / \mathrm{ONOOH}$. The decomposition of $\mathrm{ONOO}^{-} / \mathrm{ONOOH}$ can lead to the formation of $\mathrm{HO} \bullet$ and $\mathrm{NO}_{2} \bullet$ (Reactions (4)-(7)) (Pang et al. 2019). (ii) $\mathrm{N}_{2}$ purging inhibited direct oxidation of nitroso-PCMX to nitro-PCMX. This explanation is supported by previous studies showing that the nitrophenols observed in $\mathrm{UV} / \mathrm{NO}_{2}{ }^{-}$ system were at least partly derived from direct oxidation of nitrosophenols with $\mathrm{O}_{2}$ (Vione et al., 2001). However, the decay pro- file of nitro-PCMX under anaerobic condition was similar to that observed in control experiment. This finding may be ascribed to the fact that the further transformation of nitro-PCMX was mediated dominantly by $\mathrm{HO} \bullet$ (see Fig. 5), whose generation was less affected by dissolved oxygen.

$$
\begin{aligned}
& \mathrm{NO}+\mathrm{O}_{2}^{\bullet-} \rightarrow \mathrm{ONOO}^{-} \\
& \mathrm{NO} \bullet+\mathrm{HO}_{2}^{\bullet} \rightarrow \mathrm{ONOOH} \\
& \mathrm{ONOO}^{-}+\mathrm{H}^{+} \leftrightarrow \mathrm{ONOOH} \\
& \mathrm{ONOOH} \rightarrow \mathrm{NO}_{2}^{\bullet}+\mathrm{HO} \bullet \\
& \mathrm{NO} \bullet+\mathrm{O}_{2} \rightarrow \mathrm{ONOO}^{\bullet} \\
& \mathrm{NO} \bullet+\mathrm{ONOO} \bullet \rightarrow \mathrm{ONOONO}^{\bullet} \\
& \mathrm{ONOONO} \rightarrow 2 \mathrm{NO}_{2}^{\bullet}
\end{aligned}
$$

The addition of $i$-PrOH $(10 \mathrm{mM})$ did not affect the formation rate of nitro-PCMX significantly (Fig. 6), consistent with the low reactivities between $i$-PrOH and $\mathrm{RNS}$ (e.g., $\mathrm{NO}_{2}{ }^{\bullet}$ and $\mathrm{NO}^{\bullet}$ ) (Zhou et al., 2020). However, the presence of $i$-PrOH slowed the decay rate of nitro-PCMX, suggesting that $\mathrm{HO} \bullet$ was the leading oxidant for further transformation of nitro-PCMX (vide supra). This is reasonable considering that nitrated byproducts are more recalcitrant than their parent compound and are resistant to oxidation by RNS (Chen et al., 2020). The above results led us to speculate that other HO scavengers, such as NOM, may also retard the decay of nitro-derivatives in $\mathrm{UV}_{365} / \mathrm{NO}_{2}{ }^{-}$system, which warrants further investigations.

\subsection{Effects of water matrices}

NOM that is ubiquitously present in natural waters may have significant impacts on $\mathrm{NO}_{2}{ }^{-}$-sensitized photolysis of organic contaminants (Minero et al., 2007). Fig. 7 shows that the presence of MRNOM, as a representative of aquatic NOM, inhibited the degradation of PCMX and $\mathrm{CP}$ in $\mathrm{UV}_{365} / \mathrm{NO}_{2}{ }^{-}$system, and the inhibitory
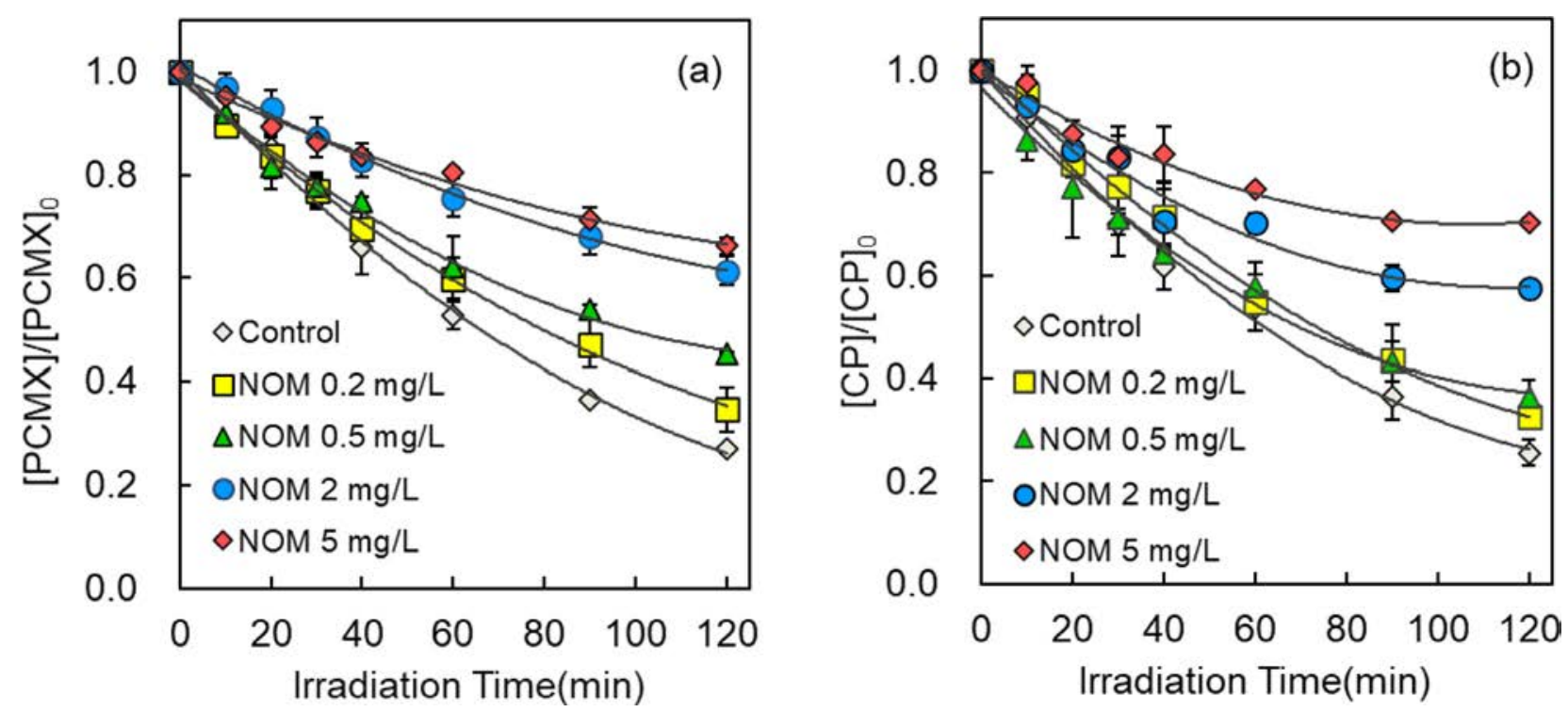

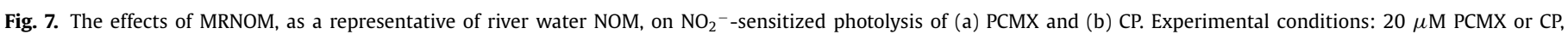
$100 \mu \mathrm{M} \mathrm{NO}_{2}^{-}, 1 \mathrm{mM}$ phosphorate buffer $(\mathrm{pH} 7.0)$. Error bars represent the standard deviations $(\mathrm{n}=2)$. 
effect was exacerbated as MRNOM concentration increased. For example, when MRNOM concentration was elevated from 0 to 5 $\mathrm{mgL}^{-1}$, the observed $k_{\text {obs }}$ value of PCMX decreased from $0.0109 \pm$ 0.0002 to $0.0037 \pm 0.0003 \mathrm{~min}^{-1}$. It should be noted that no photosensitizing effects of MRNOM (via triplet excited state $\left({ }^{3} \mathrm{NOM}^{*}\right)$ or ROS) were observed(data not shown). The inhibitory effect of MRNOM can be rationalized by following reasons. First, the chromophores of NOM, such as aryl ketones, are capable of absorbing photons at $365 \mathrm{~nm}$ wavelength (McNeill and Canonica, 2016), thus limiting the generation of reactive species by $\mathrm{NO}_{2}{ }^{-}$photolysis. On the other hand, the electron-rich moieties (ERMs) of MRNOM, such as phenolic groups, have a potential to scavenge reactive radicals (Aeschbacher et al., 2010). These results imply that when wastewater is released into rivers, the photolysis of contaminants sensitized by $\mathrm{NO}_{2}^{-}$can be reduced, mostly likely due to the light screening and radical quenching capacity of river water NOM.

$\mathrm{NO}_{2}{ }^{-}$-sensitized photolysis of PCMX and CP was also found to be appreciable in wastewater and wetland water matrices (Fig. S10, SI), in agreement with a previous study (Scholes et al., 2019). This result highlights the potential importance of $\mathrm{NO}_{2}{ }^{-}$photosensitization to the attenuation of antimicrobial agents in real water matrices upon solar radiation. It is interesting to note that, while wastewater contained greater level of NOM $(10.5 \mathrm{mg} / \mathrm{L} \mathrm{TOC})$ than wetland water $(5.0 \mathrm{mg} / \mathrm{L} \mathrm{TOC})$, higher degradation rate constants of PCMX and CP were observed in the former matrix. One possible reason is the very high alkalinity of wetland water (Table S1 of SI), which may affect the photochemistry of $\mathrm{NO}_{2}^{-}$(Chiron et al., 2009). It is well-known that bicarbonate and carbonate, the major contributors of alkalinity, are important $\mathrm{HO} \bullet$ scavengers in fresh waters, and the resulting carbonate radical $\left(\mathrm{CO}_{3}{ }^{-}\right)$can significantly scavenge $\mathrm{NO}_{2}{ }^{\bullet}$ (Reactions (11)-(13)) (Chiron et al., 2009).

$$
\begin{aligned}
& \mathrm{HO} \cdot+\mathrm{HCO}_{3}^{-} \rightarrow \mathrm{CO}_{3}^{--}+\mathrm{OH}^{-}, k=8.5 \times 10^{6} \mathrm{M}^{-1} s^{-1} \\
& \mathrm{HO} \cdot+\mathrm{CO}_{3}^{2-} \rightarrow \mathrm{CO}_{3}^{--}+\mathrm{H}_{2} \mathrm{O}, k=3.9 \times 10^{8} \mathrm{M}^{-1} s^{-1} \\
& \mathrm{NO}_{2}+\mathrm{CO}_{3}^{--} \rightarrow \mathrm{NO}_{3}^{-}+\mathrm{CO}_{2}, k=3.5 \times 10^{9} \mathrm{M}^{-1} s^{-1}
\end{aligned}
$$

\section{Conclusions and environmental implications}

Exposure of aqueous PCMX and $\mathrm{CP}$ solutions to $\mathrm{UV}_{365}$ radiation in the presence of trace level $\mathrm{NO}_{2}{ }^{-}$led to the rapid decay of these antimicrobial agents. The $\mathrm{NO}_{2}{ }^{-}$-sensitized photolysis proceeded mainly through $\mathrm{HO} \bullet$ and $\mathrm{NO}_{2} \bullet$ attack, leading to the formation of a series of intermediate products including hydroxylated, nitrated, nitrosated, and dimerized derivatives. The photolysis rate constants of PCMX and CP increased significantly with increasing concentration of $\mathrm{NO}_{2}^{-}$; but decreased in the presence of MRNOM likely due to light screening and radical quenching. The competitive kinetic experiments showed that the second-order rate constants between $\mathrm{HO} \cdot$ and $\mathrm{PCMX} / \mathrm{CP}$ are near diffusion-controlled limit. On the other hand, the second-order rate constants between $\mathrm{NO}_{2}{ }^{\bullet}$ and PCMX/CP were determined to be $2.3 \times 10^{4}$ and $1.1 \times 10^{4}$ $\mathrm{M}^{-1} \mathrm{~S}^{-1}$, respectively, by kinetic modeling, highlighting the potential importance of $\mathrm{NO}_{2}^{-}$photosensitization to the attenuation of PCMX and $\mathrm{CP}$ in sunlit surface waters containing high concentration of $\mathrm{NO}_{2}{ }^{-}$(e.g., effluent-dominated surface waters). The evolution of nitrated byproduct, nitro-PCMX, was dependent on reaction conditions such as dissolved oxygen and $\mathrm{HO} \bullet$ scavengers. In particular, HO• scavengers inhibited the further transformation of nitrated byproducts due to limited formation of $\mathrm{HO} \bullet$. It should be emphasized that the photolysis of $\mathrm{NO}_{2}{ }^{-}$generates $\mathrm{NO}_{3}{ }^{-}$as a less toxic final product; however, the potential formation of nitrated derivatives should be scrutinized due to their carcinogenicity and mutagenicity. Therefore, solar radiation may play a dual role in the attenuation of trace organic contaminants and detoxification of $\mathrm{NO}_{2}{ }^{-}$in wastewater effluents or effluent-receiving surface waters.

\section{Declaration of competing interest}

The authors declare that they have no known competing financial interests or personal relationships that could have appeared to influence the work reported in this paper.

\section{Acknowledgements}

The authors gratefully acknowledge financial support from the National Natural Science Foundation of China (Grant No. 22076080 and 22076079). We thank the anonymous reviewers for their valuable comments and constructive suggestions.

\section{References}

Aeschbacher, M., Graf, C., Schwarzenbach, R.P., Sander, M., 2010. Antioxidant properties of humic substances. Environ. Sci. Technol. 46, 4916-4925.

Baeza, C., Knappe, D.R.U., 2011. Transformation kinetics of biochemically active compounds in low-pressure UV photolysis and $\mathrm{UV} / \mathrm{H}_{2} \mathrm{O}_{2}$ advanced oxidation processes. Water Res 45, 4531-4543.

Barletta, B., Bolzacchini, E., Meinardi, S., Orlandi, M., Rindone, B., 2000. The $\mathrm{NO}_{3}$ radical-mediated liquid phase nitration of phenols with nitrogen dioxide. Environ. Sci. Technol. 34, 2224-2230.

Barzaghi, P., Herrmann, H., 2002. A mechanistic study of the oxidation of phenol by $\mathrm{OH} / \mathrm{NO} 2 / \mathrm{NO} 3$ in aqueous solution. Phys. Chem. Chem. Phys. 4, 3669-3675.

Bedini, A., Maurino, V., Minero, C., Vione, D., 2012. Theoretical and experimental evidence of the photonitration pathway of phenol and 4-chlorophenol: a mechanistic study of environmental significance. Photochem. Photobiol. Sci. 11, 418-424 2012

Capkin, E., Ozcelep, T., Kayis, S., Altinok, I., 2017. Antimicrobial agents, triclosan, chloroxylenol, methylisothiazolinone and borax, used in cleaning had genotoxic and histopathologic effects on rainbow trout. Chemosphere 182, 720-729.

Chen, C., Wu, Z., Zheng, S., Wang, L., Niu, X., Fang, J., 2020. Comparative study for interactions of sulfate radical and hydroxyl radical with phenol in the presence of nitrite. Environ. Sci. Technol. 54, 8455-8463.

Chen, P., Lv, W., Chen, Z., Ma, J., Li, R., Yao, K., Liu, G., Li, F., 2015. Phototransformation of mefenamic acid induced by nitrite ions in water: mechanism, toxicity, and degradation pathways. Environ. Sci. Pollut. Res. 22, 12585-12596.

Chiron, S., Barbati, S., Khanra, S., Dutta, B.K., Minella, M., Minero, C., Maurino, V., Pelizzetti, E., Vione, D., 2009. Bicarbonate-enhanced transformation of phenol upon irradiation of hematite, nitrate, and nitrite. Photochem. Photobiol. Sci. 8, 91-100.

Clewley, R.G., Cross, G.G., Fischer, A., Henderson, G.N., 1989. Formation of 4-halo-4-nitrocyclohexa-2,5-dienones on nitration of p-halophenols and p-halophenyl acetates. Tetrahedron 45 (5), 1299-1310.

De Laurentiis, E., Minella, M., Berto, S., Maurino, V., Minero, C., Vione, D., 2015. The fate of nitrogen upon nitrite irradiation: formation of dissolved vs. gas-phase species. J. Photochem. Photobiol. A: Chem. 307-308, 30-34.

Dulin, D., Mill, T., 1982. Development and evaluation of sunlight actinometers. Environ. Sci. Technol. 16, 815-820.

Dzengel, J., Theurich, J., Bahnemann, D.W., 1999. Formation of nitroaromatic compounds in advanced oxidation processes: photolysis versus photocatalysis. Environ. Sci. Technol. 33, 294-300.

Elias, G., Mincher, B.J., Mezyk, S.P., Muller, J., Martin, L.R., 2011. Toluene nitration in irradiated nitric acid and nitrite solutions. Rad. Phys. Chem. 80, 554-560.

Fischer, M., Warneck, P., 1996. Photodecomposition of nitrite and undissociated nitrous acid in aqueous solution. J. Phys. Chem. 100, 18749-18756.

García Einschlag, F.S., Felice, J.I., Triszcz, J.M., 2009. Kinetics of nitrobenzene and 4-nitrophenol degradation by UV irradiation in the presence of nitrate and nitrite ions. Photochem. Photobiol. Sci. 8, 953-960.

Ge, J., Huang, D., Han, Z., Wang, X., Wang, X., Wang, Z., 2019. Photochemical behavior of benzophenone sunscreens induced by nitrate in aquatic environments. Water Res 153, 178-186.

Gligorovski, S., Strekowski, R., Barbati, S., Vione, D., 2015. Environmental implications of hydroxyl radicals $(\bullet \mathrm{OH})$. Chem. Rev. 115, 13051-13092.

Ji, Y., Shi, Y., Yang, Y., Yang, P., Wang, L., Lu, J., Li, J., Zhou, L., Ferronato, C., Chovelon, J.M., 2019a. Rethinking sulfate radical-based oxidation of nitrophenols: formation of toxic polynitrophenols, nitrated biphenyls and diphenyl ethers. J. Hazard. Mater. 361, 152-161.

Ji, Y., Wang, L., Jiang, M., Lu, J., Ferronato, C., Chovelon, J.M., 2017. The role of nitrite in sulfate radical-based degradation of phenolic compounds: an unexpected nitration process relevant to groundwater remediation by in-situ chemical oxidation (ISCO). Water Res 123, 249-257. 
Ji, Y., Yang, Y., Wang, L., Lu, J., Ferronato, C., Chovelon, J.M., 2019b. Sulfate radical-induced incorporation of $\mathrm{NO}_{2}$ group into chlorophenols. Environ. Chem. Lett. 17, 1111-1116.

Ji, Y., Yang, Y., Zhou, L., Wang, L., Lu, J., Ferronato, C., Chovelon, J.M., 2018. Photodegradation of sulfasalazine and its human metabolites in water by UV and UV/peroxydisulfate processes. Water Res 133, 299-309.

Juksu, K., Zhao, J., Liu, Y., Yao, L., Sarin, C., Sreesai, S., Klomjek, P., Jiang, Y., Ying, G., 2019. Occurrence, fate and risk assessment of biocides in wastewater treatment plants and aquatic environments in Thailand. Sci. Total Environ. 690, 1110-1119.

Kieber, R.J., Li, A., Seaton, P.J., 1999. Production of nitrite from the photodegradation of dissolved organic matter in natural waters. Environ. Sci. Technol. 33, 993-998.

Kocour Kroupova, H., Valentova, O., Svobodova, Z., Sauer, P., Machova, J., 2018. Toxic effects of nitrite on freshwater organisms: a review. Rev. Aquacult. 10, 525-542.

Kolkman, A., Martijn, B.J., Vughs, D., Baken, K.A., van Wezel, A.P., 2015. Tracing nitrogenous disinfection byproducts after medium pressure UV water treatment by stable isotope labeling and high resolution mass spectrometry. Environ. Sci. Technol. 49, 4458-4465.

Kovacic, P., Somanathan, R., 2014. Nitroaromatic compounds: environmental toxicity, carcinogenicity, mutagenicity, therapy and mechanism. J. Appl. Toxicol. 34, 810-824.

Kroflič, A., Huš, M., Grilc, M., Grgić, I., 2018. Underappreciated and complex role of nitrous acid in aromatic nitration under mild environmental conditions: The case of activated methoxyphenols. Environ. Sci. Technol. 52, 13756-13765.

Li, W., Guo, H., Wang, C., Zhang, Y., Cheng, X., Wang, J., Yang, B., Du, E., 2020. ROS reevaluation for degradation of 4-chloro-3,5-dimethylphenol (PCMX) by UV and $\mathrm{UV} /$ persulfate processes in the water: kinetics, mechanism, DFT studies and toxicity evolution. Chem. Eng. J. 390, 124610.

Machado, F., Boule, P., 1995. Photonitration and photonitrosation of phenolic derivatives induced in aqueous solution by excitation of nitrite and nitrate ions. J. Photochem. Photobiol. A: Chem. 86, 73-80.

Mack, J., Bolton, J.R., 1999. Photochemistry of nitrite and nitrate in aqueous solution: a review. J. Photochem. Photobiol. A: Chem. 128, 1-13.

Maddigapu, P.R., Vione, D., Ravizzoli, B., Minero, C., Maurino, V., Comoretto, L., Chiron, S., 2010. Laboratory and field evidence of the photonitration of 4-chlorophenol to 2-nitro-4-chlorophenol and of the associated bicarbonate effect. Environ. Sci. Pollut. Res. 17, 1063-1069.

McNeill, K., Canonica, S., 2016. Triplet state dissolved organic matter in aquatic photochemistry: reaction mechanisms, substrate scope, and photophysical properties. Environ. Sci.: Processes Impacts 18, 1381-1399.

Michael, I., Rizzo, L., McArdell, C.S., Manaia, C.M., Merlin, C., Schwartz, T., Dagot, C., Fatta-Kassinos, D., 2013. Urban wastewater treatment plants as hotpots for the release of antibiotics in the environment: a review. Water Res 47 (3), 957-995.

Miklos, D.B., Hartl, R., Michel, P., Lindeng, K.G., Drewes, J.E., Hübner, U., 2018. $\mathrm{UV} / \mathrm{H}_{2} \mathrm{O}_{2}$ process stability and pilot-scale validation for trace organic chemical removal from wastewater treatment plant effluents. Water Res 136, 169-179.

Minero, C., Chiron, S., Falletti, G., Maurino, V., Pelizzetti, E., Ajassa, R., Carlotti, M.E., Vione, D., 2007. Photochemical processes involving nitrite in surface water samples. Aquat. Sci. 69, 71-85

Mvula, E., Schuchmann, M.N., von Sonntag, C., 2001. Reactions of phenol-OH-adduct radicals. Phenoxyl radical formation by water elimination vs. oxidation by dioxygen. J. Chem. Soc. Perkin Trans. 2, 264-268.

Nélieu, S., Shankar, M.V., Kerhoas, L., Einhorn, J., 2008. Phototransformation of monuron induced by nitrate and nitrite ions in water: contribution of photonitration. J. Photochem. Photobiol. A: Chem. 193, 1-9.

Pang, H., Zhang, Q., Lu, X., Li, K., Chen, H., Chen, J., Yang, X., Ma, Y., Ma, J., Huang, C., 2019. Nitrite-mediated photooxidation of vanillin in the atmospheric aqueous phase. Environ. Sci. Technol. 53, 14253-14263.
Patnaik, P., Khoury, J.N., 2004. Reaction of phenol with nitrite ion: pathways of formation of nitrophenols in environmental waters. Water Res 38, 206-210.

Pignatello, J.J., Oliveros, E., MacKay, A., 2006. Advanced oxidation processes for organic contaminant destruction based on the fenton reaction and related chemistry. Crit. Rev. Environ. Sci. Technol. 36 (1), 1-84.

Qu, R., Xu, B., Meng, L., Wang, L., Wang, Z., 2015. Ozonation of indigo enhanced by carboxylated carbon natotubes: performance optimization, degradation products, catalytic mechanism and toxicity evaluation. Water Res 68, 316-327.

Scholes, R.C., Prasse, C., Sedlak, D.L., 2019. The role of reactive nitrogen species in sensitized photolysis of wastewater-derived trace organic contaminants. Environ. Sci. Technol. 53 (11), 6483-6491.

Shankar, M.V., Nélieu, S., Kerhoas, L., Einhorn, J., 2007. Photo-induced degradation of diuron in aqueous solution by nitrites and nitrates: kinetics and pathways. Chemosphere 66, 767-774.

Shankar, M.V., Nélieu, S., Kerhoas, L., Einhorn, J., 2008. Natural sunlight $\mathrm{NO}_{3}{ }^{-} / \mathrm{NO}_{2}{ }^{-}$-induced photo-degradation of phenylurea herbicides in water. Chemosphere 71, 1461-1468.

Shenghur, A., Weber, K.H., Nguyen, N.D., Sontising, W., Tao, F.M., 2014. Theoretical study of the hydrogen abstraction of substituted phenols by nitrogen dioxide as a source of HONO. J. Phys. Chem. A 118, 11002-11014.

Sreevidya, V.S., Lenz, K.A., Svoboda, K.R., Ma, H., 2018. Benzalkonium chloride, benzethonium chloride, and chloroxylenol-three replacement antimicrobials are more toxic than triclosan and triclocarban in two model organisms. Environ. Pollut. 235, 814-824.

Vione, D., Maurino, V., Minero, C., Borghesi, D., Lucchiari, M., Pelizzetti, E., 2003. New processes in the environmental chemistry of nitrite. 2 . The role of hydrogen peroxide. Environ. Sci. Technol. 37, 4635-4641.

Vione, D., Maurino, V., Minero, C., Lucchiari, M., Pelizzetti, E., 2004. Nitration and hydroxylation of benzene in the presence of nitrite/nitrous acid in aqueous solution. Chemosphere 56, 1049-1059.

Vione, D., Maurino, V., Minero, C., Pelizzetti, E., 2001. Phenol photonitration upon UV irradiation of nitrite in aqueous solution I: effects of oxygen and 2-propanol. Chemosphere 45, 893-902.

Vione, D., Maurino, V., Minero, C., Pelizzetti, E., 2002. New processes in the environmental chemistry of nitrite: nitration of phenol upon nitrite photoinduced oxidation. Environ. Sci. Technol. 36, 669-676.

Vione, D., Maurino, V., Minero, C., Pelizzetti, E., 2005. Nitration and photonitration of naphthalene in aqueous system. Environ. Sci. Technol. 39, 1101-1110.

Xu, L., Sun, Y., Gan, L., Han, J., Wang, P., Yu, L., Mei, X., Li, W., Lyu, B., Pei, C., Chu, W. 2019. Utilization of photochemical circulation between $\mathrm{NO}_{3}{ }^{-}$and $\mathrm{NO}_{2}{ }^{-}$in water to degrade photoinert dimethyl phthalate: influence of organic media and mechanism study. Appl. Catal. B: Environ. 259, 117958.

Yang, X., Ding, X., Zhou, L., Fan, H., Wang, X., Ferronato, C., Chovelon, J.M., Xiu, G., 2020. New insights into clopyralid degradation by sulfate radical: Pyridine ring cleavage pathways. Water Res, 115378.

Zeng, X., Qu, R., Feng, M., Chen, J., Wang, L., Wang, Z., 2016. Photodegradation of Polyfluorinated Dibenzo-p-Dioxins (PFDDs) in Organic Solvents: Experimental and Theoretical Studies. Environ. Sci. Tech. 50, 8128-8134.

Zhao, X., Zhang, T., Lu, J., Zhou, L., Chovelon, J.M., Ji, Y., 2020. Formation of chloronitrophenols upon sulfate radical-based oxidation of 2-chlorophenol in the presence of nitrite. Environ. Pollut. 261, 114242.

Zhou, S., Li, L., Wu, Y., Zhu, S., Zhu, N., Bu, L., Dionysiou, D.D., 2020. UV 365 induced elimination of contaminants of emerging concern in the presence of residual nitrite: roles of reactive nitrogen species. Water Res 178, 115829. 